\title{
A Cascade PI-SMC Method for Matrix Converter- fed BDFIM Drives
}

\author{
Hui Wang, Xida Chen, Student Member, IEEE, Xun Zhao, Hanbing Dan, Mei Su, Member, \\ IEEE, Yao Sun, Member, IEEE, Fan Zhang, Marco Rivera, Senior Member, IEEE, and \\ Patrick Wheeler, Fellow, IEEE
}

\begin{abstract}
This paper proposes a cascade proportional-integral second-order sliding mode control (PI-SMC) method for matrix converter-fed brushless doubly-fed induction machine (BDFIM). The PI-SMC method consists of a PI speed controller with an inner-loop second-order SMC. The PI controller provides a reference to the inner-loop second-order SMC with constraints according to the system requirements in terms of maximum current and speed. As the discontinuous sign function in the traditional SMC is replaced by the continuous super-twisting function, the chattering problem is eliminated for inner-loop second-order SMC. Moreover, the inner-loop second-order SMC has robustness and interference immunity against non-linear disturbances of the BDFIM. Simulation and Experimental results demonstrate the excellent robust tracking performance of the proposed PI-SMC method.
\end{abstract}

Index Terms-Brushless Doubly-Fed Induction Machine, Cascade PI-SMC method, Matrix Converter.

\section{INTRODUCTION}

$\mathrm{T}$ HE brushless doubly-fed induction machine (BDFIM) [1]-[3] is a type of AC induction machine which has been developed from two cascaded asynchronous motors. Compared to the doubly-fed induction machine (DFIM), the BDFIM inherits the advantages of the doubly-fed machine and has higher reliability as it cancels the slip rings or brushes. Moreover, the BDFIM has a wider range of speed regulation. Therefore, the BDFIM has received extensive attention from researchers [4], [5] and has a broad range of potential applications in the field of variable-speed drive applications [6]

Manuscript received September 05, 2020; revised November 21, 2020; accepted February 15, 2021. This work was supported in part by the Hunan Provincial Key Laboratory of Power Electronics Equipment and Grid under Grant 2018TP1001, in part by the National Natural Science Foundation of China under Grant 61903382, 61873289, 61933011, in part by the National Key R\&D Program of China under Grant 2018YFB0606005, in part by the Natural Science Foundation of Hunan Province, China under Grant 2020JJ5722. (Corresponding author: Hanbing Dan)

Hui Wang, Xida Chen, Xun Zhao, Hanbing Dan, Mei Su and Yao Sun are with the Hunan Provincial Key Laboratory of Power Electronics Equipment and Gird, School of Automation, Central South University, Changsha, 410083 China (email: wanghuicp9@csu.edu.cn, Xida.Chen_CSU@csu.edu.cn, FLYzhaoxun@csu.edu.cn,_daniel698@sina.cn,_sumeicsu@csu.edu.cn, yaosuncsu@gmail.com).

Fan Zhang is with the GAC R\&D Center, Guangzhou, 511434 China (e-mail: wriftfan@163.com).

M. Rivera is with the Department of Electrical Engineering, Universidad de Talca, Curico, PB, 3341717 Chile (e-mail: marcoesteban@gmail.com).

P. Wheeler is with Power Electronics \& Machine Control (PEMC) research group at the University of Nottingham, Nottingham NG7 2RD, U.K. (e-mail: Pat.Wheeler@nottingham.ac.uk). and wind power generation [7]. As a promising alternative to the traditional back-to-back converter, matrix converter is employed for the BDFIM drive system in wind power generation application [8], [9]. Since matrix converter [10]-[12] can realize direct AC-AC conversion without using an intermediate DC link, this feature of matrix converter will bring several advantages to the matrix converter-fed BDFIM drive systems, such as high-power density and long lifetime.

Many control strategies have been proposed for BDFIM drive system, such as scalar control [13]-[15], direct torque control (DTC) [16], [17], model predictive control (MPC) [5], [9], and vector control [7], [8], [18]-[22]. Several scalar control methods have been proposed for the BDFIM system, such as open-loop control [13], closed-loop frequency control [14], and phase angle control [15]. However, the scalar control relies on the static analysis of the BDFM, which makes it only fit for industrial applications with low-performance requirements. In [16], [17], the DTC method for the BDFIG system is proposed. The proper switching vector is chosen by analyzing the effects of different switching vectors on flux and torque. The DTC method has a simple structure and fast dynamic response. However, the torque fluctuation is a disadvantage of this technique. The MPC method has advantages such as conceptual simplicity and easiness of implementation, fast dynamic response, easy inclusion of nonlinearities and constraints of the system, and the flexibility to include other system requirements in the controller [23]. In [9], a predictive torque control strategy has been proposed for controlling the flux and torque of a matrix converter-fed brushless doubly-fed induction generator (BDFIG). The system model is used to predict the system variable and evaluate the switching vector. The optimal switching vector with the minimum cost function value is applied during the next sample period. However, the unmatched model parameters will lead to inaccurate prediction of the motor behavior and deteriorate the performance and stability of the MPC method. The vector control methods based on different flux orientation frames are proposed [8], [18]-[20], [22]. Wallace et al. developed the dynamic vector model of the BDFIM with an arbitrary pole number referred to the rotor's shaft position [24]. The BDFIM model is built in power winding (PW) and control winding $(\mathrm{CW})$ synchronous reference frames related to each pole-pair distribution. The vector control technique implementation is complex for the rotor flux-oriented control method in [18]. The combined magnetizing flux-oriented control for the cascaded doubly-fed induction machine is studied in [19]. The rotor current vector is oriented into an artificial magnetizing flux reference frame based on the two stator currents measurements. However, this 
control method does not lead to natural decoupled active and reactive power control. Thus, the PW flux-oriented vector control strategy [20] is proposed based on a unified reference-frame model in [25]. It is simple to be implemented. Meanwhile, the natural decoupled active and reactive power control is obtained. Thus, the PW flux-oriented vector control method is usually adopted [8], [22]. In [8], the cascaded double closed-loops control method is adopted for a matrix converterfed BDFM system, including one fast inner current control loop and one outer flux/speed control loop. However, the inner current loop plant of the BDFIM has a complex non-linear structure and is susceptible to various disturbances. Thus, the robust controller is required for the inner-loop.

Since the Slide Mode Control (SMC) [26] has the advantages of easy decoupling, disturbance rejection and parameter variation insensitivity, it has been applied as an alternative robust solution for the induction motor drive applications [27], [28]. For traditional back-to-back inverter-fed BDFIM drive system, the integral SMC method is employed in the outer-loop speed controller [21]. However, the traditional SMC has the phenomenon of "chattering" because the switch does not have the ideal switching characteristics, which will affect the control effect of the system to a certain extent. Therefore, a second-order sliding mode controller based on super twisting is considered a more suitable method for practical applications due to its continuity and robustness. The second-order sliding mode controller eliminates the chattering problem without affecting the tracking accuracy and robustness.

To obtain high robust tracking performance, this paper proposes a cascade PI-second-order SMC for the matrix converter-fed BDFIM drive system. In this method, the out-loop PI controller tracks the reference rotor speed, and the inner-loop SMC controller regulates the $\mathrm{CW}$ current. The main advantages of this method are that the outer loop controller provides constraints on the SMC through maximum current and speed limits and the second-order SMC controller achieves fast and fixed convergence times for the current control loop. Meanwhile, the parameter variations of the BDFIM are considered in the design of the inner-loop SMC controller. The proposed PI-SMC method in this paper has been described in [29], more theoretical details and experimental results are added in this paper.

The rest of this paper is organized as follows. In Section II, the mathematical model and operation principle of matrix converter are described firstly, and the mathematical model of BDFIM drives is presented. Section III shows the sliding mode control of the matrix converter-fed BDFIM. Then in Sections IV and $\mathrm{V}$, the simulation and experiment for matrix converter-fed BDFIM drives are carried out to verify the proposed PI-SMC method. Finally, Section VI concludes the findings.

\section{Mathematical Model OF THE Matrix CONVERTER-Fed BDFIM}

\section{A. Mathematical Model and Operation Principle of the Matrix Converter}

The basic structure of the matrix converter-fed BDFIM is shown in Fig. 1. The relationship between the output and the input voltage of the matrix converter is shown as follow:

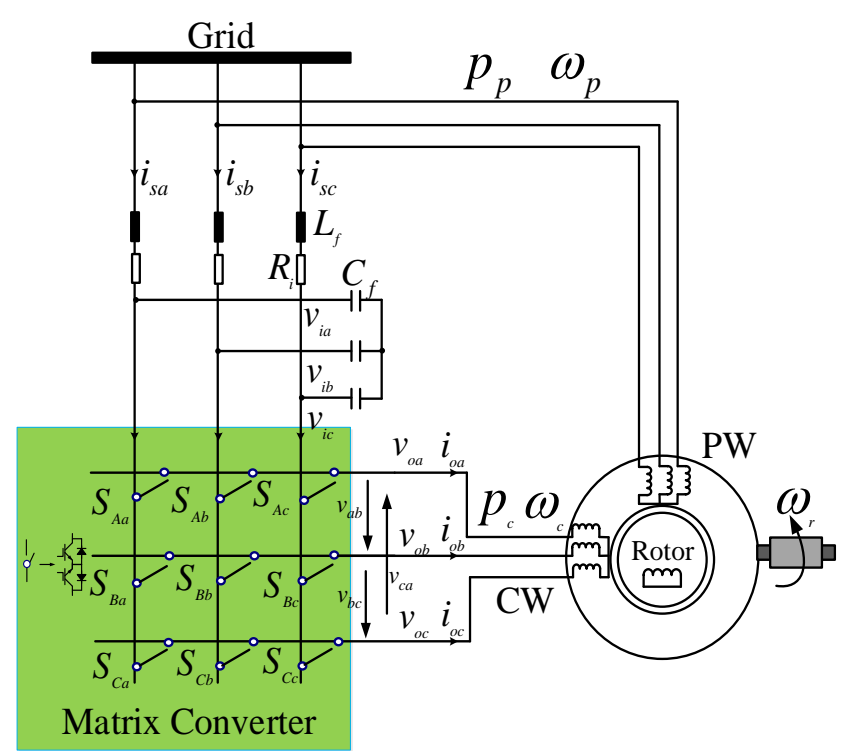

Fig. 1. The basic structure of the matrix converter-fed BDFIM drives.

$$
\left[\begin{array}{c}
v_{o a} \\
v_{o b} \\
v_{o c}
\end{array}\right]=\left[\begin{array}{lll}
S_{A a} & S_{A b} & S_{A c} \\
S_{B a} & S_{B b} & S_{B c} \\
S_{C a} & S_{C b} & S_{C c}
\end{array}\right]\left[\begin{array}{c}
v_{i a} \\
v_{i b} \\
v_{i c}
\end{array}\right]
$$

where $v_{o y}(y \in\{a, b, c\})$ is the output voltage of the matrix converter and $v_{i y}(y \in\{a, b, c\})$ is the input voltage of the matrix converter. Each group of switching state needs to meet $S_{x a}+S_{x b}+S_{x c}=1,(x \in\{A, B, C\})$. The modulation method based on mathematical construction [30] is used in this paper.

The switching functions can be replaced by the corresponding duty cycles as the switching frequency is much higher than the input/output frequencies. Thus, equation (1) can be written as:

$$
\left[\begin{array}{l}
v_{o a} \\
v_{o b} \\
v_{o c}
\end{array}\right]=M\left[\begin{array}{l}
v_{i a} \\
v_{i b} \\
v_{i c}
\end{array}\right]
$$

where $M$ is the duty cycle matrix and is expressed as

$$
M=\left[\begin{array}{lll}
m_{11} & m_{12} & m_{13} \\
m_{21} & m_{22} & m_{23} \\
m_{31} & m_{32} & m_{33}
\end{array}\right]=\left[\begin{array}{lll}
m_{11}^{\prime \prime}+x+D & m_{12}^{\prime \prime}+y+D & m_{13}^{\prime \prime}+z+D \\
m_{21}^{\prime \prime}+x+D & m_{22}^{\prime \prime}+y+D & m_{23}^{\prime \prime}+z+D \\
m_{31}^{\prime \prime}+x+D & m_{32}^{\prime \prime}+y+D & m_{33}^{\prime \prime}+z+D
\end{array}\right] \text { (3) }
$$

Define the transition modulation matrix $M$ " as:

$$
\begin{aligned}
M^{\prime \prime} & =\left[\begin{array}{lll}
m_{11}^{\prime \prime} & m_{12}^{\prime \prime} & m_{13}^{\prime \prime} \\
m_{21}^{\prime \prime} & m_{22}^{\prime \prime} & m_{23}^{\prime \prime} \\
m_{31}^{\prime \prime} & m_{32}^{\prime \prime} & m_{33}^{\prime \prime}
\end{array}\right] \\
& =K\left[\begin{array}{c}
\cos \left(\omega_{0} t\right) \\
\cos \left(\omega_{0} t-2 \pi / 3\right) \\
\cos \left(\omega_{0} t+2 \pi / 3\right)
\end{array}\right]\left[\begin{array}{c}
\cos \left(\omega_{i} t-\theta_{i}\right) \\
\cos \left(\omega_{i} t-\theta_{i}-2 \pi / 3\right) \\
\cos \left(\omega_{i} t-\theta_{i}+2 \pi / 3\right)
\end{array}\right]^{T}
\end{aligned}
$$

where $\omega_{i}, \theta_{i}, \omega_{0}$ and $K$ represent input angular frequency, input power factor angle, output angular frequency and modulation index, respectively. Besides, to meet non-negative constraints of the duty cycles, $x, y, z$ needs to satisfy (5): 


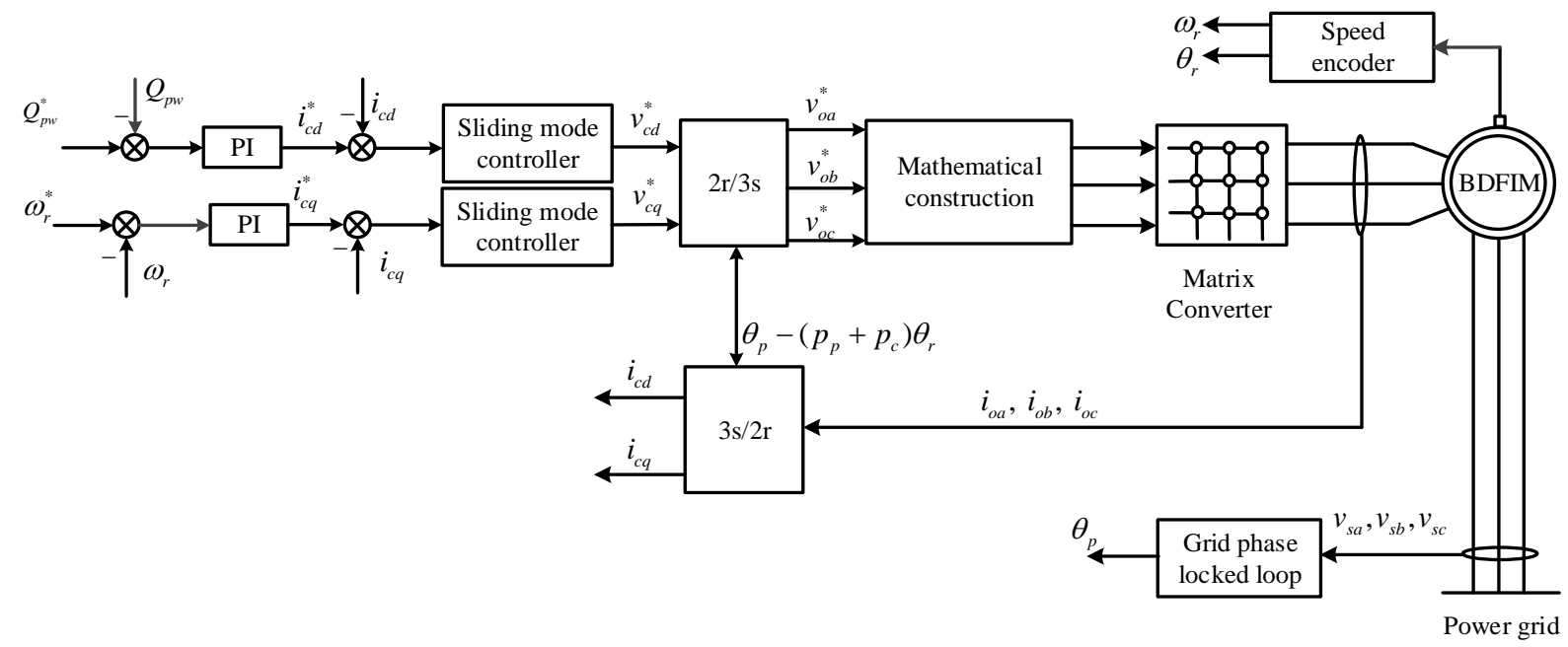

Fig. 2. Sliding mode control diagram of the matrix converter-fed BDFIM drives.

$$
\left\{\begin{array}{l}
x \geq-\min \left(m_{11}^{\prime \prime}, m_{21}^{\prime \prime}, m_{31}^{\prime \prime}\right) \\
y \geq-\min \left(m_{12}^{\prime \prime}, m_{22}^{\prime \prime}, m_{32}^{\prime \prime}\right) \\
z \geq-\min \left(m_{13}^{\prime \prime}, m_{23}^{\prime \prime}, m_{33}^{\prime \prime}\right)
\end{array}\right.
$$

To make the algorithm as simple as possible, the boundary values in (5) are usually adopted. At the same time, the modulation matrix $M$ also needs to satisfy that the sum of elements in each row is 1. Therefore, an offset D is superimposed on each row in $\mathrm{M}$, and $\mathrm{D}$ can be selected as $D=[1-(x+y+z)] / 3, D \geq 0$.

The mathematical construction-based modulation method can obtain the duty cycles of nine switches directly in the matrix converter, which is simple and can achieve the maximum voltage transfer ratio of 0.866 .

\section{B. Mathematical Model of the BDFIM Drives}

The BDFIM consists of three windings: PW, CW and rotor winding $(\mathrm{RW})$. The power stator side is usually directly connected with the grid side voltage, so the rotating speed of the stator magnetic field on the power side is known and remains unchanged. Therefore, the $d-q$ reference frame based on the PW flux orientation is selected. The voltages and currents vectors of $\mathrm{PW}, \mathrm{CW}$, and RW are represented as $x_{p}, x_{c}$, and $x_{r}$, respectively. These vectors are transformed from their reference frames to the $d-q$ reference frame using the following corresponding equations.

$$
\left\{\begin{array}{l}
\boldsymbol{x}_{\boldsymbol{p}}^{d \boldsymbol{q}}=e^{-j \omega_{p} t} \boldsymbol{x}_{\boldsymbol{p}}^{\alpha \beta p} \\
\boldsymbol{x}_{\boldsymbol{c}}^{d \boldsymbol{q}}=e^{-j\left(\omega_{p}-\left(p_{p}+p_{c}\right) \omega_{r}\right) t}\left(-\boldsymbol{x}_{\boldsymbol{c}}^{\alpha \beta p}\right)^{*} \\
\boldsymbol{x}_{\boldsymbol{r}}^{d \boldsymbol{q}}=e^{-j\left(\omega_{p}-p_{p} \omega_{r}\right) t} \boldsymbol{x}_{\boldsymbol{r}}^{\alpha \beta p}
\end{array}\right.
$$

where $\omega_{p}$ and $\omega_{c}$ are the angular frequencies of $\mathrm{PW}$ and $\mathrm{CW}$, respectively; $P_{p}$ and $P_{c}$ are pole pairs of $\mathrm{PW}$ and $\mathrm{CW}$, respectively; $\omega_{r}$ is the angular speed of the rotor. To simplify the expressions, the vector superscripts $d q$ is removed.

Since the rotor resistance is small to be ignored and the rotor flux is nearly zero, using the synchronous rotating coordinate system of power stator as reference coordinate system, the simplified mathematical model of the BDFIM [31] is derived as:

$$
\left\{\begin{array}{l}
\boldsymbol{v}_{\boldsymbol{p}}=R_{p} \boldsymbol{i}_{\boldsymbol{p}}+\frac{d \psi_{p}}{d t}+j \omega_{p} \boldsymbol{\psi}_{\boldsymbol{p}} \\
\boldsymbol{v}_{\boldsymbol{c}}=R_{c} \boldsymbol{i}_{\boldsymbol{c}}+\frac{d \psi_{c}}{d t}-j \omega_{c} \boldsymbol{\psi}_{\boldsymbol{c}} \\
0=R_{r} \boldsymbol{i}_{\boldsymbol{r}}+\frac{d \psi_{r}}{d t}+j \omega_{r} \boldsymbol{\psi}_{\boldsymbol{r}} \\
\boldsymbol{\psi}_{\boldsymbol{r}}=L_{r} \boldsymbol{i}_{\boldsymbol{r}}+M_{p} \boldsymbol{i}_{\boldsymbol{p}}+M_{c} \boldsymbol{i}_{\boldsymbol{c}} \\
\boldsymbol{\psi}_{\boldsymbol{p}}=L_{p} \boldsymbol{i}_{\boldsymbol{p}}+M_{p} \boldsymbol{i}_{\boldsymbol{r}} \\
\boldsymbol{\psi}_{\boldsymbol{c}}=L_{c} \boldsymbol{i}_{\boldsymbol{c}}+M_{c} \boldsymbol{i}_{\boldsymbol{r}} \\
T_{e}=\frac{3}{2} p_{p} \operatorname{Im}\left[\left(\boldsymbol{\psi}_{p}\right)^{*} \boldsymbol{i}_{p}\right]+\frac{3}{2} p_{c} \operatorname{Im}\left[\left(\boldsymbol{\psi}_{c}\right)^{*} \boldsymbol{i}_{\boldsymbol{c}}\right] \\
Q_{p w}=\frac{3 v_{p q}}{2\left(L_{r} L_{p}-M_{p}^{2}\right)} M_{p} M_{c} i_{c d}+\frac{3 L_{r} v_{p q}^{2}}{2\left(L_{r} L_{p}-M_{p}^{2}\right) \omega_{p}} \\
J \frac{d \omega_{r}}{d t}=T_{e}-T_{L}-B_{g} \omega_{r}
\end{array}\right.
$$

where $v_{p}, v_{c}, i_{p}, i_{c}, i_{r}, \psi_{c}$ and $\psi_{r}$ are the power winding stator voltage vector, $\mathrm{CW}$ stator voltage vector, $\mathrm{PW}$ stator current vector, CW stator current vector, rotor current vector, $\mathrm{PW}$ stator flux vector, CW stator flux vector and rotor flux vector in the $d$ - $q$ rotating coordinate system; $R_{p}, R_{c}, R_{r}, L_{p}, L_{c}$ and $L_{r}$ are the PW stator resistance, CW stator resistance, rotor resistance, PW stator inductance, CW stator inductance and rotor inductance; $M_{p}$ is the coupling inductance between the PW stator and rotor winding; $M_{c}$ is the coupling inductance between the $\mathrm{CW}$ stator and rotor winding; $T_{e}$ is the electromagnetic torque; ()* is the conjugate symbol; $\operatorname{Im}[]$ is a symbol to obtain the imaginary part of vector; $J$ and $B_{g}$ are the moments of inertia and friction coefficient; $T_{L}$ is the load torque; $Q_{p w}$ is the reactive power. When the rotor resistance and the rotor flux are not considered, according to (7), the voltage equation of the BDFIM can be expressed as:

$$
\left\{\begin{array}{l}
\frac{d i_{c d}}{d t}=-\frac{\sigma_{1} R_{c}}{\sigma_{2}} i_{c d}+\frac{\sigma_{1}}{\sigma_{2}} v_{c d}-\omega_{c} i_{c q} \\
\frac{d i_{c q}}{d t}=-\frac{\sigma_{1} R_{c}}{\sigma_{2}} i_{c q}+\frac{\sigma_{1}}{\sigma_{2}} v_{c q}+\omega_{c} i_{c d}+D_{1}
\end{array}\right.
$$

where $\psi_{p m}$ is the amplitude of the PWstator flux vector, $\sigma_{1}=L_{p} L_{r}-M_{p}^{2}, \sigma_{2}=L_{c} L_{p} L_{r}-M_{c}^{2} L_{p}-M_{p}^{2} L_{c}$ and $D_{1}=M_{p} M_{c} \psi_{p m} / \sigma_{2}$.

\section{Sliding Model CONTROL OF THE MATRIX CONVERTER-} FED BDFIM 
The SMC diagram for the matrix converter-fed BDFIM is shown in Fig. 2. The control method adopts a double closed-loop control structure. The outer loops use the conventional PI control strategy to track the reactive power of the PW and the reference rotor speed. The output of the outer loop controller is the reference stator current of the inner loop control. To improve the robustness and interference immunity ability of the non-linear inner-loop dynamics, a second-order SMC method is introduced as the current loop to obtain the reference voltage of the $\mathrm{CW}$ and the duty cycles of the matrix converter.

\section{A. Current Loop Design}

According to the nonlinear system shown in (8), in order to achieve zero steady-state error tracking of $i_{c d}^{*}$ and increase the degree of freedom in system bandwidth adjustment, the sliding mode surface is selected as

$$
S_{s l}=X_{1}+\lambda_{1} X_{2}
$$

where $X_{1}=i_{c d}-i_{c d}^{*}, X_{2}=\int i_{c d}-i_{c d}^{*} d t, \lambda_{1}$ is the sliding mode coefficient to adjust the current loop bandwidth. When the sliding occurs, i.e. $S_{s l}=0, \dot{S}_{s l}=0$, the steady-state error $i_{c d}$ can be expressed as:

$$
X_{1}(t)=X_{1}(0) e^{\lambda_{1} t}
$$

The control law of the sliding mode controller is selected as shown in (11):

$$
\left\{\begin{array}{l}
v_{c d}=v_{c d}^{e q}+v_{c d}^{s t} \\
v_{c d}^{e q}=\left(\frac{\sigma_{1} R_{c}}{\sigma_{2}} i_{c d}+\omega_{c} i_{c q}+\frac{d i_{c d}^{*}}{d t}-\lambda_{1} X_{1}\right) \frac{\sigma_{2}}{\sigma_{1}} \\
v_{c d}^{s t}=-c_{1}\left|S_{s l}\right|^{\frac{1}{2}} \operatorname{sign}\left(S_{s l}\right)-c_{2} \int \operatorname{sign}\left(S_{s l}\right) d t
\end{array}\right.
$$

where $v_{c d}^{e q}$ is the equivalent control and $v_{c d}^{s t}$ is a super-twist control item, $c_{1}$ and $c_{2}$ are the positive constants, respectively.

Considering that the high-frequency noise can be presented in the system, it is not easy to obtain the derivative of $i_{c d}^{*}$. In order to solve this problem, this solution uses a second-order sliding mode differentiator as shown in (12) to obtain the derivative of $i_{c d}^{*}$. Supposing $i_{c d}^{*}$ contains Langberg measurement noise, and $\left(d i_{c d}^{*} / d t\right)<L$, then:

$$
\left\{\begin{array}{l}
\dot{z}_{0}=v_{0}, v_{0}=-\beta_{0} L^{1 / 3}\left|z_{0}-i_{c d}^{*}\right|^{2 / 3} \operatorname{sign}\left(z_{0}-i_{c d}^{*}\right)+z_{1} \\
\dot{z}_{1}=v_{1}, v_{1}=-\beta_{1} L^{1 / 2}\left|z_{0}-v_{0}\right|^{1 / 2} \operatorname{sign}\left(z_{0}-v_{0}\right)+z_{2} \\
\dot{z}_{2}=-\beta_{2} \operatorname{Lign}\left(z_{2}-v_{1}\right)
\end{array}\right.
$$

In (12), the parameter selection method in terms of $\beta_{0}, \beta_{1}, \beta_{2}$ can refer to the literature [32]. In the absence of input noise, the following equation is true after a finite time transient process.

$$
\left\{\begin{array}{l}
z_{0}=i_{c d}^{*} \\
v_{0}=z_{1}=\frac{d i_{c d}^{*}}{d t}
\end{array}\right.
$$

\section{B. Speed Loop Design}

The outer speed loop adopts the conventional PI controller. According to (8), the mathematical model of the BDFIM can be expressed as

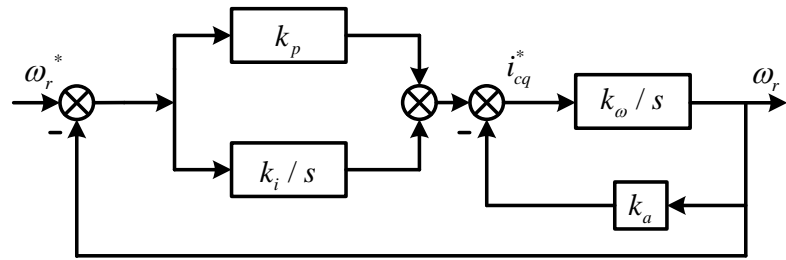

Fig. 3. The block diagram of speed outer loop with active damping item.

$$
J \frac{d \omega_{r}}{d t}=\frac{3 M_{p} M_{c}\left(p_{p}+p_{c}\right) \psi_{p m}}{2\left(L_{p} L_{r}-M_{p}^{2}\right)} i_{c q}-T_{L}-B_{g} \omega_{r}
$$

and the item $B_{g} \omega_{r}$ can usually be treated as the disturbance part. The factor of $i_{c q}$ is represented by $k_{\omega}$, then equation (14) can be simplified as

$$
\frac{d \omega_{r}}{d t}=k_{\omega} i_{c q}
$$

Assuming the inner loop's bandwidth is 10 times the bandwidth of the outer loop, the speed equation (15) is regarded as a first-order speed system. The control block diagram of the outer loop is shown in Fig. 3, and the PI controller with active damping item [33] is applied in this manuscript.

$$
i_{c q}^{*}=k_{p}\left(\omega_{r}^{*}-\omega_{r}\right)+k_{i} \int_{0}^{t}\left(\omega_{r}^{*}-\omega_{r}\right) d t-k_{a} \omega_{r}
$$

The closed-loop transfer function of the system is obtained as:

$$
\Phi(s)=\frac{k_{\omega}\left(k_{p} s+k_{i}\right)}{s^{2}+k_{\omega}\left(k_{p}+k_{a}\right) s+k_{\omega} k_{i}}
$$

where $V_{d c}$ represents the DC-side voltage, and $\alpha$ is the angle between the reference voltage vector $\boldsymbol{V}_{\boldsymbol{r e f}}$ and the voltage basis vector $\boldsymbol{V}_{\mathbf{1}}$.

In this manuscript, the parameter of the active damp item is selected as $k_{a}=k_{p}$. The closed-loop transfer function of the speed control loop is designed as an inertial link in a first-order system with $\omega_{a c}$ as the bandwidth.

$$
\Phi(s)=\frac{\omega_{a c}}{s+\omega_{a c}}
$$

According to the equation (17) and (18), the parameter of the PI controller is calculated as $k_{p}=\omega_{a c} / k_{\omega}, k_{i}=\omega_{a c}^{2} / k_{\omega}, k_{a}=\omega_{a c} / k_{\omega}$.

\section{Robust Analysis and Proof of Stability}

Considering the physical limitation of the system in practice and its behavior during the operation, such as eddy current loss and parameter uncertainties, the second-order sliding mode control method is applied to the current inner loop to improve the system stability and anti-disturbance ability [32].

According to (8) and (11), considering the parameters variation, the unmodeled dynamics and any other external disturbances, the current differential equation of the BDFIM with disturbance is shown in (19):

$$
\begin{aligned}
\frac{d i_{c d}}{d t}= & -\frac{\hat{\sigma}_{1} \hat{R}_{c}}{\hat{\sigma}_{2}} i_{c d}+\frac{\hat{\sigma}_{1}}{\hat{\sigma}_{2}} v_{c d}-\omega_{c} i_{c q} \\
& +\frac{\hat{\sigma}_{1} \sigma_{2} \hat{R}_{c}-\sigma_{1} \hat{\sigma}_{2} R_{c}}{\sigma_{2} \hat{\sigma}_{2}} i_{c d}+\frac{\sigma_{1} \hat{\sigma}_{2}-\hat{\sigma}_{1} \sigma_{2}}{\sigma_{2} \hat{\sigma}_{2}} v_{c d}+\xi
\end{aligned}
$$

where $\xi$ includes the unmodeled dynamics and any other disturbances. The upper notation "^" represents the nominal 


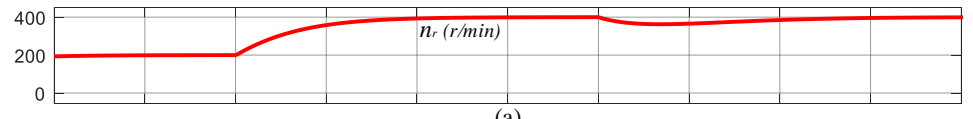

(a)

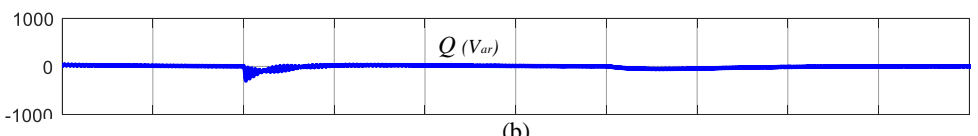

(b)
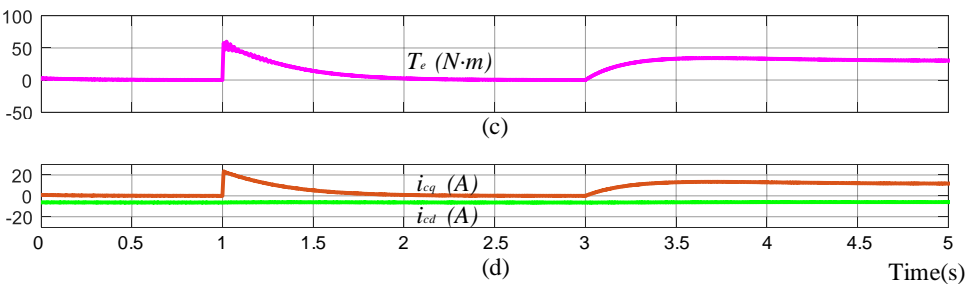

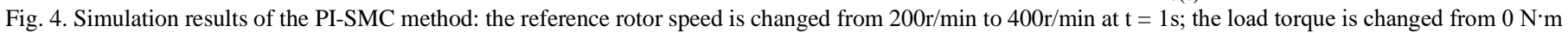
to $30 \mathrm{~N} \cdot \mathrm{m}$ at $\mathrm{t}=3 \mathrm{~s}$. (a) the rotor speed (b) the reactive power (c) the electromagnetic torque (d) $\mathrm{CW} d q$-axis stator current.

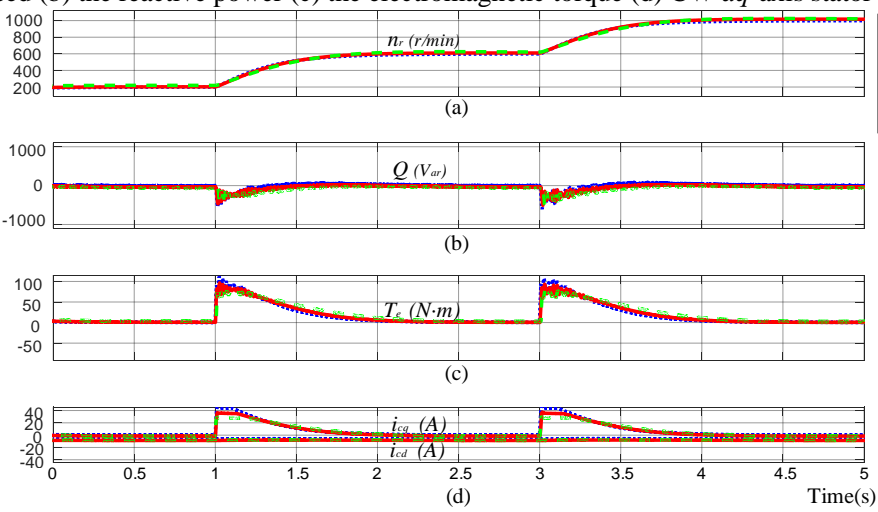

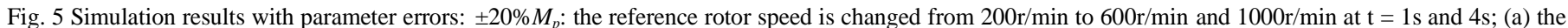
rotor speed (b) the reactive power (c) the electromagnetic torque (d) $\mathrm{CW} d q$-axis stator current.
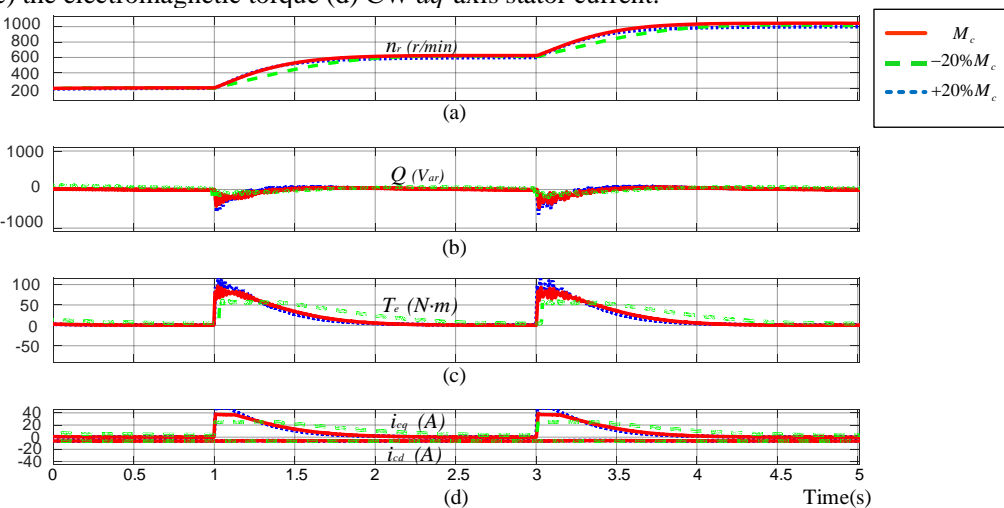

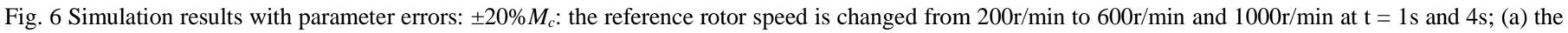
rotor speed (b) the reactive power (c) the electromagnetic torque (d) $\mathrm{CW} d q$-axis stator current.

value, after that, $\hat{\sigma}_{1}$ and $\hat{\sigma}_{2}$ are shown as

$$
\left\{\begin{array}{l}
\hat{\sigma}_{1}=\sigma_{1}+\Delta \sigma_{1}=\hat{L}_{p} \hat{L}_{r}-\hat{M}_{p}^{2} \\
\hat{\sigma}_{2}=\sigma_{2}+\Delta \sigma_{2}=\hat{L}_{c} \hat{L}_{p} \hat{L}_{r}-\hat{M}_{c}^{2} \hat{L}_{p}-\hat{M}_{p}^{2} \hat{L}_{c}
\end{array}\right.
$$

The parameter variation is shown in (21):

$$
\left\{\begin{array}{l}
\hat{L}_{r}=L_{r}+\Delta L_{r}, \hat{L}_{p}=L_{p}+\Delta L_{p}, \hat{L}_{c}=L_{c}+\Delta L_{c} \\
\hat{R}_{c}=R_{c}+\Delta R_{c}, \hat{M}_{p}=M_{p}+\Delta M_{p}, \hat{M}_{c}=M_{c}+\Delta M_{c}
\end{array}\right.
$$

where $\Delta L_{r}, \Delta L_{p}, \Delta L_{c}, \Delta M_{p}, \Delta M_{c}$ are the parametric errors, $\Delta \sigma_{1}$ and $\Delta \sigma_{2}$ in (20) denote the parameter error caused by the variation of parameters $L_{r}, L_{p}, L_{c}, M_{p}, M_{c}$, and are shown as

$$
\begin{aligned}
\Delta \sigma_{1}= & \Delta L_{r} L_{p}+L_{r} \Delta L_{p}+\Delta L_{r} \Delta L_{p}-2 M_{p} \Delta M_{p}-\Delta M_{p}^{2} \\
\Delta \sigma_{2}= & \Delta L_{c} L_{r} L_{p}+\Delta L_{r} L_{c} L_{p}+\Delta L_{p} L_{c} L_{r}+\Delta L_{c} \Delta L_{r} L_{p} \\
& +\Delta L_{c} \Delta L_{p} L_{r}+\Delta L_{r} \Delta L_{p} L_{c}+\Delta L_{c} \Delta L_{r} \Delta L_{p} \\
& -2 L_{p} M_{c} \Delta M_{c}-L_{p} \Delta M_{c}^{2}-M_{c}^{2} \Delta L_{p} \\
& -2 L_{c} M_{p} \Delta M_{p}-L_{c} \Delta M_{p}^{2}-M_{p}^{2} \Delta L_{c}
\end{aligned}
$$

For ease of analysis, the errors in (19) can be integrated into the form shown in (23):

$$
d=\frac{\hat{\sigma}_{1} \sigma_{2} \hat{R}_{c}-\sigma_{1} \hat{\sigma}_{2} R_{c}}{\sigma_{2} \hat{\sigma}_{2}} i_{c d}+\frac{\sigma_{1} \hat{\sigma}_{2}-\hat{\sigma}_{1} \sigma_{2}}{\sigma_{2} \hat{\sigma}_{2}} v_{c d}+\xi
$$

In practice, the matrix converter-fed BDFIM needs to meet certain physical constraints in operation. The following 
assumptions can be made:

(1) The capacity of the matrix converter is limited, that is, the output current and voltage are limited;

(2) The disturbance of the brushless doubly-fed induction machine is bounded. The parameter variation $\Delta L_{r}, \Delta L_{p}, \Delta L_{c}$, $\Delta M_{p}$ and $\Delta M_{c}$ are bounded.

According to the above assumption, the total disturbance is bounded as $|d| \leq \varepsilon$. $\varepsilon$ is a known positive constant, which represents the upper limit of the known current inner loop error.

According to (9) and (19), the first-order derivative of the sliding surface $S_{s l}$ is derived as

$$
S_{s l}=\dot{X}_{1}+\lambda_{1} X_{1}=\hat{X}_{1}+\lambda_{1} X_{1}+d
$$

where $\hat{X}_{1}$ is the nominal value of $X_{1}$. Substituting (11) into (24), the closed-loop system is derived as

$$
\left\{\begin{array}{l}
\dot{S}_{s l}=-c_{1}\left|S_{s l}\right|^{\frac{1}{2}} \operatorname{sign}\left(S_{s l}\right)+v+d \\
\dot{v}=-c_{2} \operatorname{sign}(S)
\end{array}\right.
$$

To prove the stability of the system, the Lyapunov function is selected as [32]

$$
\begin{aligned}
V & =2 c_{2}\left|S_{s l}\right|+\frac{1}{2} v^{2}+\frac{1}{2}\left(c_{1}\left|S_{s l}\right|^{1 / 2} \operatorname{sign}\left(S_{s l}\right)-v\right)^{2} \\
& =\zeta^{T} P_{s l} \zeta
\end{aligned}
$$

where $\zeta^{T}$ and $P_{s l}$ are expressed as

$$
\begin{aligned}
& \zeta^{T}=\left[\operatorname{sign}\left(S_{s l}\right)\left|S_{s l}\right|^{1 / 2} \quad v\right] \\
& P_{s l}=\frac{1}{2}\left[\begin{array}{cc}
4 c_{2}+c_{1}^{2} & -c_{1} \\
-c_{1} & 2
\end{array}\right]
\end{aligned}
$$

From (26), it can be derived that:

$$
\dot{V}=-\frac{1}{\left|S_{s l}\right|^{1 / 2}} \zeta^{T} Q \zeta+\frac{d}{\left|S_{s l}\right|^{1 / 2}} q^{T} \zeta
$$

where $Q$ and $q^{T}$ can be expressed as:

$$
Q=\frac{c_{1}}{2}\left[\begin{array}{cc}
2 c_{1}+c_{1}^{2} & -c_{1} \\
-c_{1} & 1
\end{array}\right], \quad q^{T}=\left[\left(2 c_{2}+\frac{c_{1}^{2}}{2}\right)-\frac{c_{1}}{2}\right]
$$

Since the disturbance of the current inner loop is bounded, it can be shown that [34]:

$$
\dot{V} \leq-\frac{1}{|S|^{(1 / 2)}} \zeta^{T} \tilde{Q} \zeta
$$

where

$$
\tilde{Q}=\frac{c_{1}}{2}\left[\begin{array}{cc}
2 c_{2}+c_{1}^{2}-\left(\frac{4 c_{2}}{c_{1}}+c_{1}\right) \varepsilon & -\left(c_{1}+2 \varepsilon\right) \\
-\left(c_{1}+2 \varepsilon\right) & 1
\end{array}\right]
$$

When $V$ is positive and $\dot{V}$ is negative, the system satisfies the asymptotic stability condition, if $\tilde{Q}>0$. Therefore, by setting the values of $c_{1}$ and $c_{2}$, the system is stable under bounded noise interference. The choice of $c_{1}$ and $c_{2}$ is shown in (33):

$$
\left\{\begin{array}{l}
c_{1}>2 \varepsilon \\
c_{2}>c_{1} \frac{5 c_{1} \varepsilon+4 \varepsilon^{2}}{2\left(c_{1}-2 \varepsilon\right)}
\end{array}\right.
$$

Therefore, the second-order sliding mode controller of $i_{c d}$ is designed according to the theory of sliding mode control, and
TABLE I

SIMULATION PARAMETERS

\begin{tabular}{ccc}
\hline \hline Symbol & Parameter & Value \\
\hline$P_{p}$ & the number of pole pairs of the PW & 1 \\
$P_{c}$ & the number of pole pairs of the CW & 3 \\
$R_{p}$ & PW stator resistance $(\Omega)$ & 0.40355 \\
$R_{c}$ & CW stator resistance $(\Omega)$ & 0.5470 \\
$R_{r}$ & rotor resistance $(\Omega)$ & 0.785244 \\
$L_{p}$ & PW stator inductance $(m \mathrm{H})$ & 253.3 \\
$L_{c}$ & CW stator inductance $(m \mathrm{H})$ & 129.6 \\
$M_{p}$ & PW excitation inductance $(m \mathrm{H})$ & 247.4 \\
$M_{c}$ & $\mathrm{CW}$ excitation inductance $(m \mathrm{H})$ & 123.7 \\
\hline \hline
\end{tabular}

TABLE II

MOTOR SPECIFICATION OF BDFIM AND IM

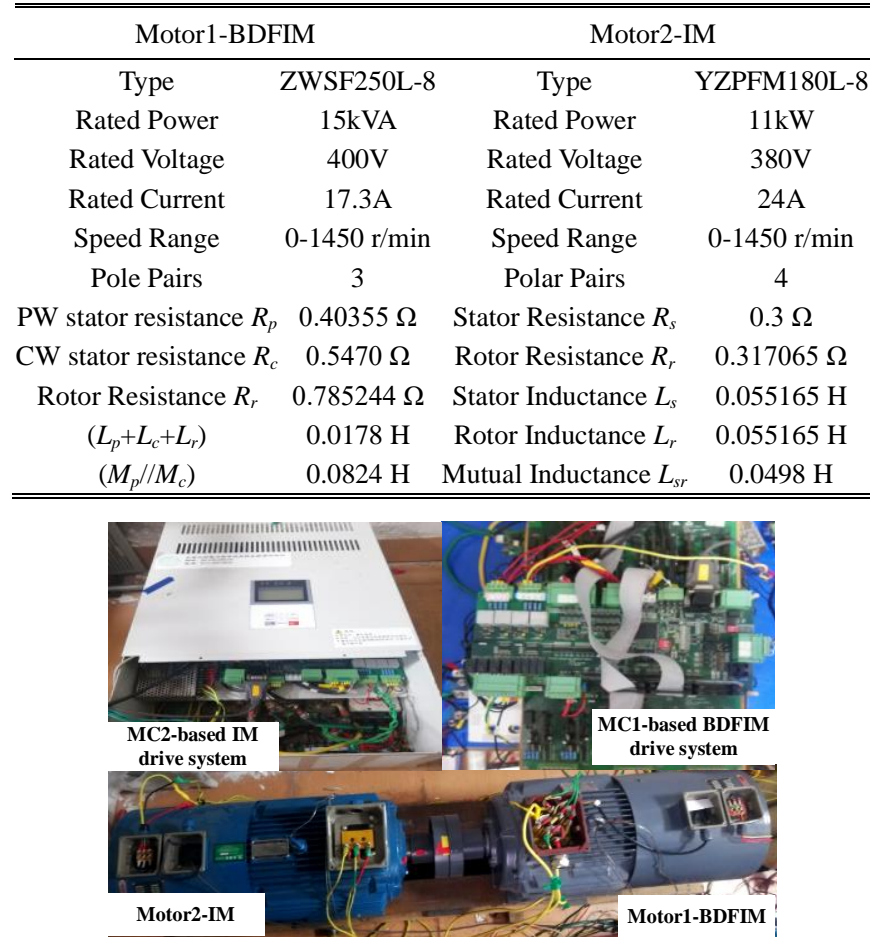

Fig. 7. Experimental setup.

its robustness is proved by mathematical method. In the same theory, the second-order sliding mode controller of $i_{c q}$ can be designed in the same way.

\section{Simulation RESUlts}

To verify the correction of the proposed method, numerical simulations are performed on MATLAB/Simulink. The parameters of BDFIM are shown in Table I.

Fig. 4 shows the simulation results of the PI-SMC method. It can be seen that the actual speed of the BDFIM reaches a steady state within 1s when the reference rotor speed changes. The steady-state error of speed is approximately zero and the reactive power fluctuates slightly and keeps to zero rapidly. When the load torque changes abruptly from $0 \mathrm{~N} \cdot \mathrm{m}$ to $30 \mathrm{~N} \cdot \mathrm{m}$, the rotor speed has a drop, but recovers in $1 \mathrm{~s}$. The reactive power is almost maintained at zero.

To simplify the analysis, the variation of parameters $M_{p}$ and $M_{c}$ are considered. The simulation results under parametric error $\pm 20 \% M_{p}$ and $\pm 20 \% M_{c}$ are presented in Figs. 5 and 6 to validate the robustness of the proposed method. The steady and 


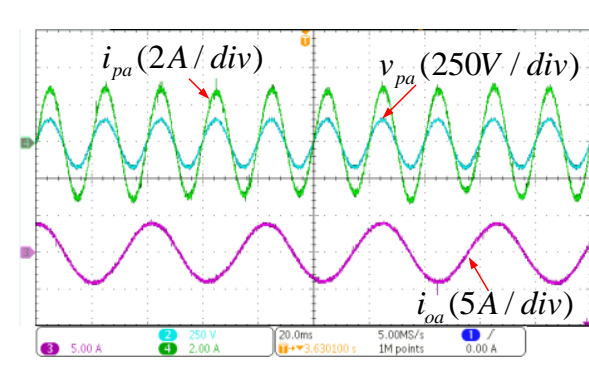

(a)

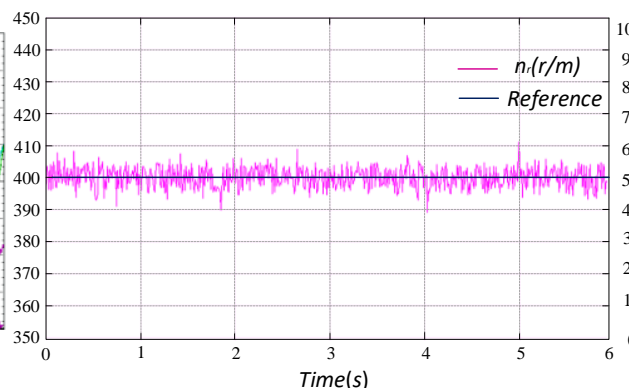

(b)

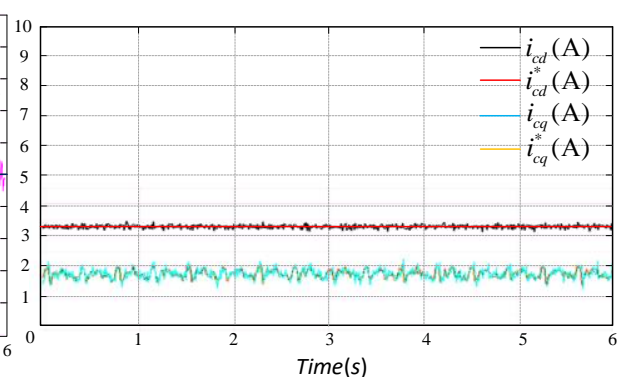

(c)

Fig. 8. Experimental results of the cascade PI-SMC method when the reference rotor speed is $400 \mathrm{r} / \mathrm{min}$. (a) Experimental waveforms of PI-SMC method (b) the reference and real values of rotor speed (c) the reference and real values of $d q$-axis $\mathrm{CW}$ stator current.

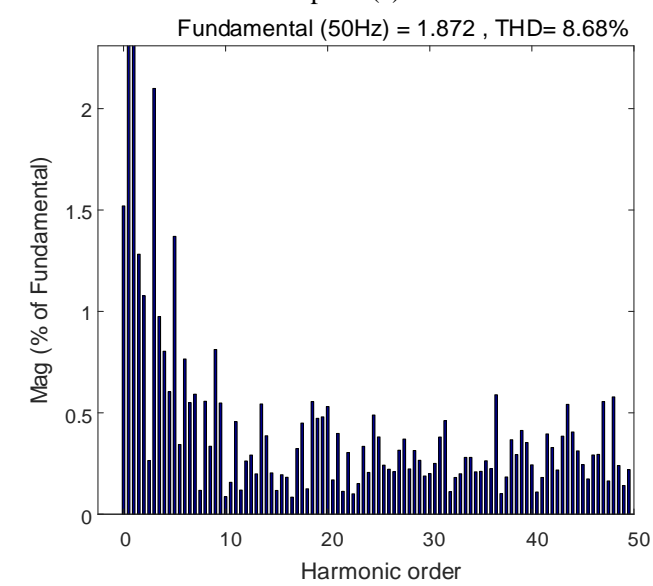

(a)

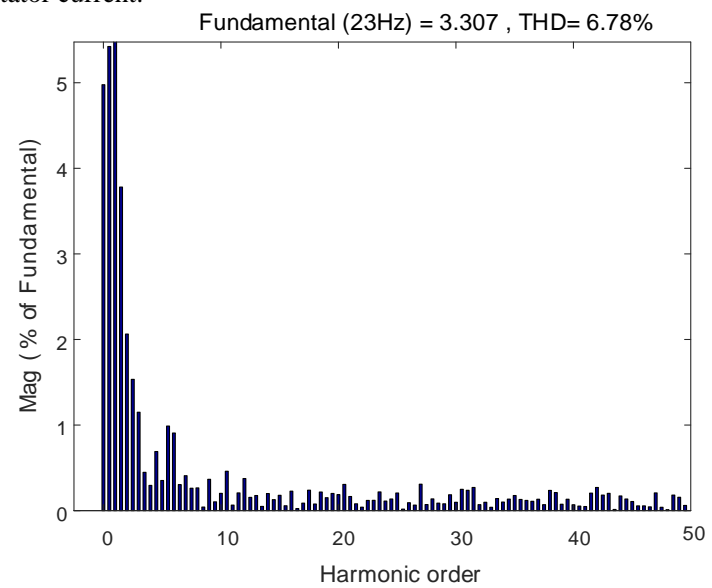

(b)

Fig. 9. The harmonic spectra of $\mathrm{PW}$ and $\mathrm{CW}$ current when the reference rotor speed is $400 \mathrm{r} / \mathrm{min}$. (a) $\mathrm{PW}$ stator current $i_{p a}$ (b) $\mathrm{CW}$ stator current $i_{o a}$.

dynamic control performances of the proposed method are different when the parameter $M_{p}$ has $\pm 20 \%$ error. Nonetheless, the tracking performances of the rotor speed and $\mathrm{CW}$ stator current are both satisfied with quick tracking processes. When the parameter $M_{c}$ has $\pm 20 \%$ error, the tracking performances of the rotor speed and $\mathrm{CW}$ stator current are both acceptable as shown in Fig. 6. In conclusion, when the parametric error exists, the waveforms in steady and dynamic states are affected to some extent. However, the system stability under variable parameters is guaranteed with suitable parameters $c_{1}$ and $c_{2}$.

\section{EXPERIMENTAL VERIFICATION}

To verify the correctness of the proposed cascade PI-SMC method for the matrix converter-fed BDFIM drive, an experimental prototype is built. The experimental system arrangement is shown in Fig. 7. The root means square value of input line-to-line voltage is $200 \mathrm{~V}$. An $11 \mathrm{~kW}$ three-phase induction motor (IM) is mechanically coupled to the $15 \mathrm{kVA}$ BDFIM and driven by a matrix converter. The matrix converter-fed BDFIM drive system consists of four parts: control platform, clamp circuit, drive system and IGBT module. The control platform mainly consists of a DSP (TMS320F28335) and Field-Programmable Gate Array (FPGA, EP2C8T144C8N). The drive system is utilized to convert the acquired duty cycle into high or low levels to drive the IGBTs of the matrix converter. The clamp circuit is equipped to prevent damage to the matrix converter caused by issues such as commutation failure or shut down. The precise values of parameters $L_{p}, L_{c}, L_{r}$, $M_{p}$ and $M_{c}$ are unknown. The data relationship between the inductors is obtained through a simple measurement. The motor specifications of BDFIM and IM are shown in Table II.

To verify the steady-state performance and dynamic performance of the proposed PI-SMC method under the condition of unknown parameters, the following tests are carried out.

\section{A. Steady-State Performance Test}

Fig. 8 (a) shows the experimental waveforms of PW stator phase voltage $v_{p a}$, PW stator current $i_{p a}$ and $\mathrm{CW}$ stator current $i_{o a}$ when the reference speed is set as $400 \mathrm{r} / \mathrm{min}$ for the matrix converter-fed BDFIM. The PW stator phase current is approximately sinusoidal and in phase with the PW stator phase voltage. Thus, the reactive power is nearly zero. The data in Fig.8 (b)-(c) is obtained through the digital-to-analog converter of the control platform. The rotor speed tracks the reference speed well, as shown in Fig. 8 (b). The steady-state error of rotor speed is $\pm 3 \mathrm{r} / \mathrm{min}$ after filtering sampling noise. The real values of $d q$-axis CW stator current are stable with small fluctuations and track the reference value well, as shown in Fig. 8 (c). The proposed PI-SMC method still has a perfect steady-state performance in the case of uncertain motor specific parameters.

The harmonic spectra of $\mathrm{PW}$ and $\mathrm{CW}$ current when the reference rotor speed is $400 \mathrm{r} / \mathrm{min}$ are shown in Fig. 9. The THD value of PW and CW current are $8.68 \%$ and $6.78 \%$, respectively. The distortion of $\mathrm{PW}$ and $\mathrm{CW}$ current are generated due to the device voltage drop, commutation dead time and other non-linear factors.

\section{B. Dynamic Performance Test}

Fig. 10 shows the experimental waveforms of PW stator phase voltage $v_{p a}$, PW stator current $i_{p a}$, and $\mathrm{CW}$ stator current 


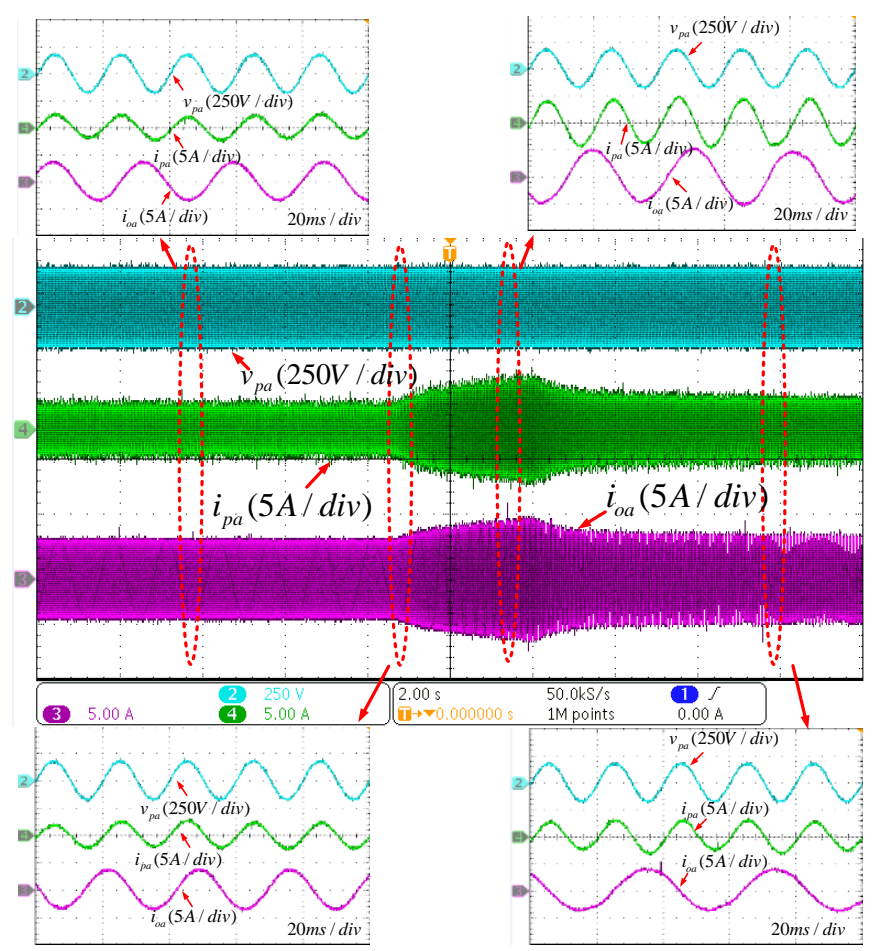

Fig. 10. Experimental waveforms of cascade PI-SMC method when the reference rotor speed changes from $200 \mathrm{r} / \mathrm{min}$ to $400 \mathrm{r} / \mathrm{min}$.

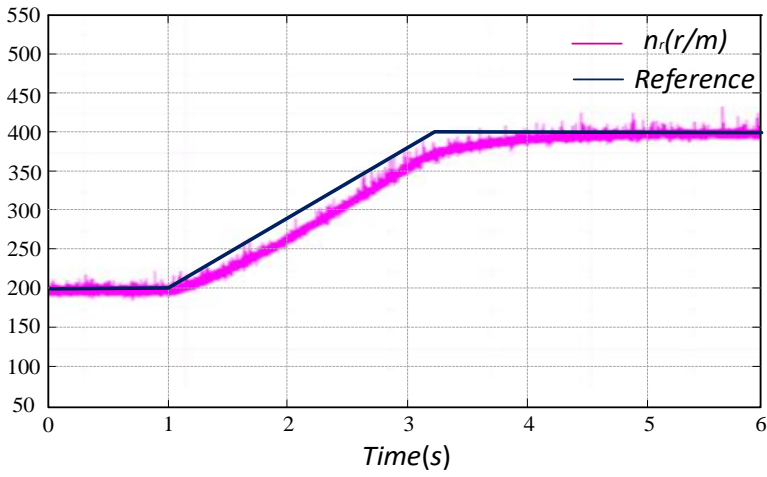

(a)

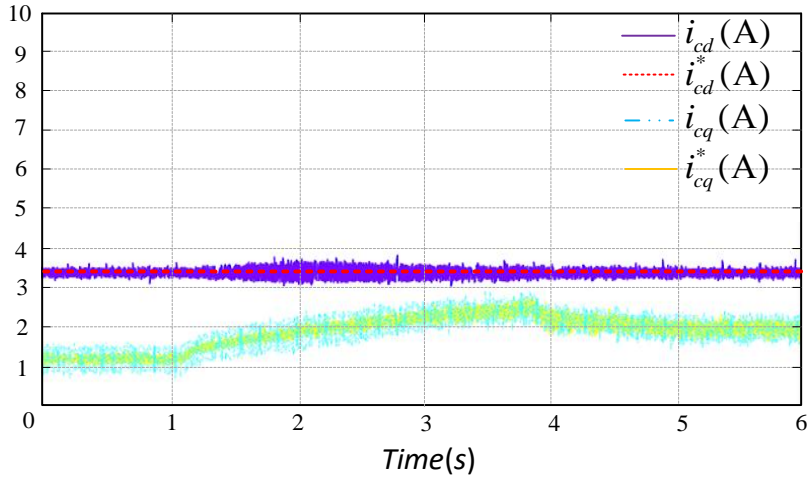

(b)

Fig. 11. Experimental waveforms of cascade PI-SMC method when the reference rotor speed changes from $200 \mathrm{r} / \mathrm{min}$ to $400 \mathrm{r} / \mathrm{min}$. (a) the reference and real values of rotor speed (b) the reference and real values of $d q$-axis $\mathrm{CW}$ stator current.

$i_{o a}$ when the reference rotor speed changes from $200 \mathrm{r} / \mathrm{min}$ to $400 \mathrm{r} / \mathrm{min}$. The enlarged drawing of the red dotted boxes in four different states are given. The PW stator current and CW stator current increase to provide larger electromagnetic torque when the reference rotor speed increase. Then PW stator current and $\mathrm{CW}$ stator current are stable after the reference rotor speed keeps constant. As shown in Fig. 11 (a), when the reference rotor speed changes, the real rotor speed can track the reference value accurately with the proposed cascade PI-SMC method. The real values of the $d q$-axis $\mathrm{CW}$ stator current track the reference value in the dynamic process, as shown in Fig. 11 (b), which shows a good dynamic performance.

Fig. 12 shows the experimental waveforms of PW stator phase voltage $v_{p a}$, PW stator current $i_{p a}$, and $\mathrm{CW}$ stator current $i_{o a}$ when the load torque changes from $0 \mathrm{~N} \cdot \mathrm{m}$ to $5 \mathrm{~N} \cdot \mathrm{m}$ and changes back to $0 \mathrm{~N} \cdot \mathrm{m}$ with a constant reference rotor speed. The enlarged drawing of the red dotted boxes in four different states are given. The PW stator current and CW stator current increase or decrease when the load torque increases or decreases. As shown in Fig. 13, a few adjustments occur in the real rotor speed and $d q$-axis $\mathrm{CW}$ stator current when the load torque changes. Then the rotor speed recovers to its original value in a short time. The proposed cascade PI-SMC method has a good anti-disturbance interference ability and achieves good dynamic performance.

\section{CONCLUSION}

In this paper, a cascade PI-SMC method is proposed for a matrix converter-fed BDFIM drive system. The proposed method consists of a PI speed controller and an inner-loop second-order SMC. The outer loop adopts the PI controller with the active damping to track the reference value of the rotor speed and reactive power. The inner loop uses the continuous super-twisting sliding mode controller to control the $\mathrm{CW}$ current of the brushless doubly-fed motor, which eliminates the chattering problem. The proposed cascade PI-SMC method has a good anti-disturbance interference ability. Meanwhile, it has excellent robust tracking performance. The experimental 


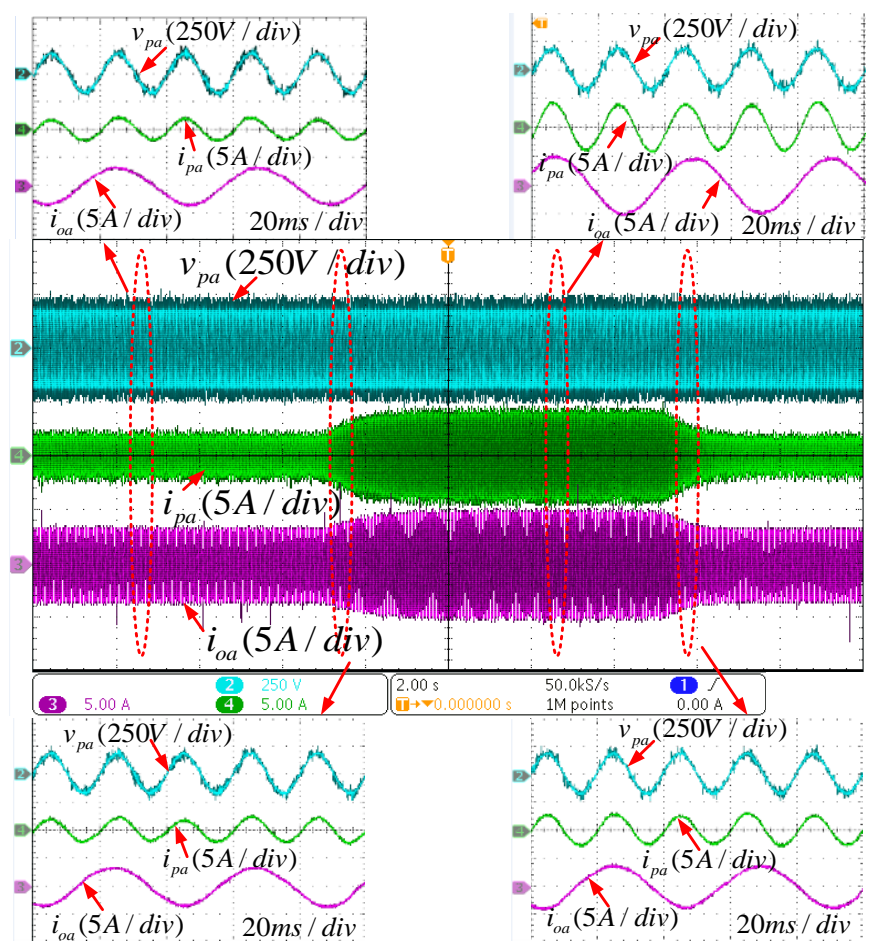

Fig. 12. Experimental waveforms of cascade PI-SMC method: the load torque changes from $0 \mathrm{~N} \cdot \mathrm{m}$ to $5 \mathrm{~N} \cdot \mathrm{m}$ and changed back to $0 \mathrm{~N} \cdot \mathrm{m}$ when the reference rotor speed is $400 \mathrm{r} / \mathrm{min}$.

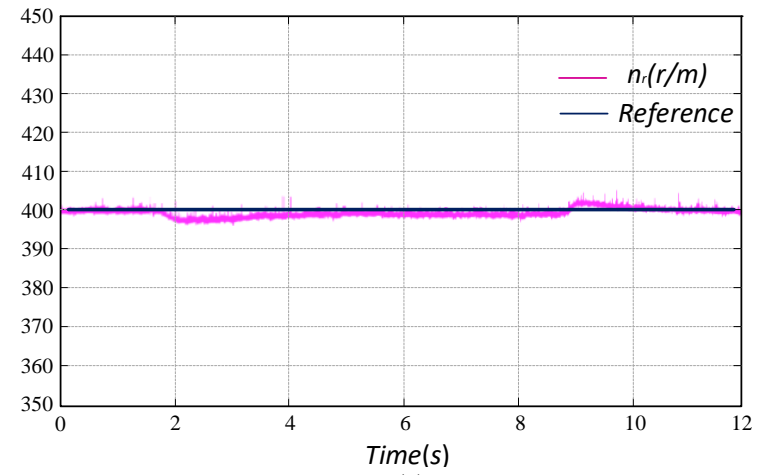

(a)

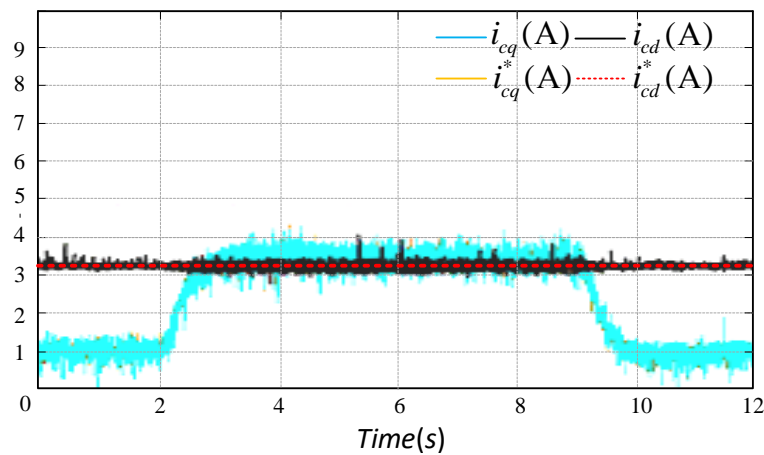

(b)

Fig. 13. Experimental results of the cascade PI-SMC method: the load torque changes from $0 \mathrm{~N} \cdot \mathrm{m}$ to $5 \mathrm{~N} \cdot \mathrm{m}$ and changed back to $0 \mathrm{~N} \cdot \mathrm{m}$ when the reference rotor speed is $400 \mathrm{r} / \mathrm{min}$. (a) the reference and real values of rotor speed (b) the reference and real $d q$-axis values of $\mathrm{CW}$ stator current.

results verify the effectiveness and correction of the proposed cascade PI-SMC method.

\section{REFERENCES}

[1] M. B. Field, H. W. Wilson and L. J. Hunt, "Discussion on 'A new type of induction motor'," Journal of the Institution of Electrical Engineers, vol. 39, no. 186, pp. 668-677, September 1907.

[2] P. Han, M. Cheng, S. Ademi and M. G. Jovanovic, "Brushless doubly-fed machines: Opportunities and challenges," Chinese Journal of Electrical Engineering, vol. 4, no. 2, pp. 1-17, June 2018.

[3] M. E. Mathekga, S. Ademi and R. A. McMahon, "Brushless doubly fed machine magnetic field distribution characteristics and their impact on the analysis and design," IEEE Transactions on Energy Conversion, vol. 34, no. 4, pp. 2180-2188, Dec. 2019.

[4] Y. Liu, W. Xu, J. Zhu and F. Blaabjerg, "Sensorless control of standalone brushless doubly fed induction generator feeding unbalanced loads in a ship shaft power generation system," IEEE Transactions on Industrial Electronics, vol. 66, no. 1, pp. 739-749, Jan. 2019.

[5] Xuan Li, Tao Peng, Hanbing Dan, Guanguan Zhang, Weiyi Tang, Weiyu Jin, Patrick Wheeler, Marco Rivera, "A modulated model predictive control scheme for the brushless doubly-fed induction machine," IEEE
Journal of Emerging and Selected Topics in Power Electronics, vol. 6, no.4, pp. 1681-1691,2018.

[6] S. Shao, E. Abdi and R. McMahon, "Low-cost variable speed drive based on a brushless doubly-fed motor and a fractional unidirectional converter," IEEE Transactions on Industrial Electronics, vol. 59, no. 1, pp. 317-325, Jan. 2012.

[7] J. Chen, W. Zhang, B. Chen and Y. Ma, "Improved vector control of brushless doubly fed induction generator under unbalanced grid conditions for offshore wind power generation," IEEE Transactions on Energy Conversion, vol. 31, no. 1, pp. 293-302, March 2016.

[8] R. Cárdenas, R. Peña, P. Wheeler, J. Clare, A. Muñoz, A. Sureda, "Control of a wind generation system based on a brushless doubly-fed induction generator fed by a matrix converter", Electric Power Syst. Res, vol. 103, pp. 49-60, Oct. 2013.

[9] S. Bayhan, P. Kakosimos, M. Rivera, "Predictive torque control of brushless doubly fed induction generator fed by a matrix converter," in IEEE 12th International Conference on Compatibility, Power Electronics and Power Engineering, 2018.

[10] P. W. Wheeler, J. Rodriguez, J. C. Clare, L. Empringham, and A. Wein-stein, "Matrix converters: A technology review," IEEE Trans. Ind. Electron, vol. 49, no. 2, pp. 276-288, Apr. 2002.

[11] M. Khosravi, M. Amirbande, D. A. Khaburi, M. Rivera, J. Riveros, J. Rodriguez, A. Vahedi, P. Wheeler, "Review of model predictive control 
strategies for matrix converters," IET Power Electronics, vol. 12, no. 12, pp. 3021-3032, 2019.

[12] Friedli T, Kolar J W, Rodriguez J, et al. "Comparative evaluation of three-phase AC-AC matrix converter and voltage DC-link back-to-back converter systems," IEEE Transactions on industrial electronics, vol. 59, no.12, pp. 4487-4510, 2011.

[13] D. Zhou, R. Spee and A. K. Wallace, "Laboratory control implementations for doubly-fed machines," Proceedings of IECON '93 19th Annual Conference of IEEE Industrial Electronics, Maui, HI, USA, 1993, pp. 1181-1186.

[14] Ruqi Li, R. Spee, A. K. Wallace and G. C. Alexander, "Synchronous drive performance of brushless doubly-fed motors," IEEE Transactions on Industry Applications, vol. 30, no. 4, pp. 963-970, July-Aug. 1994.

[15] S. Y. Shao, E. Abdi, and R. A. McMahon, "Low-cost variable speed drive based on a brushless doubly-fed motor and a fractional unidirectional converter," IEEE Trans. Ind. Electron., vol. 59, no. 1, pp. 317-325. Jan. 2012.

[16] W. R. Brassfield, R. Spee and T. G. Habetler, "Direct torque control for brushless doubly-fed machines," IEEE Transactions on Industry Applications, vol. 32, no. 5, pp. 1098-1104, Sep/Oct 1996.

[17] R. Sadeghi, S. M. Madani and M. Ataei, "A new smooth synchronization of brushless doubly-fed induction generator by applying a proposed machine model," IEEE Transactions on Sustainable Energy, vol. 9, no. 1, pp. 371-380, Jan. 2018.

[18] D. Zhou, R. Spee, and G. C. Alexander, "Experimental evaluation of a rotor flux oriented control algorithm for brushless doubly-fed machines," IEEE Trans. Power Electron., vol. 12, no. 1, pp. 72-78, Jan. 1997.

[19] B. Hopfensperger, D. J. Atkinson, and R. A. Lakin, "Combined magnetizing flux oriented control of the cascaded doubly-fed induction machine," IEE Proc. Electr. Power Appl., vol. 148, no. 4, pp. 354-362, Jul. 2001

[20] J. Poza, E. Oyarbide, I. Sarasola, M. Rodriguez, "Vector control design and experimental evaluation for the brushless doubly fed machine," IET Elect. Power Appl, vol. 3, no. 4, pp. 247-256, Jul. 2009.

[21] G. Zhang, J. Yang, Y. Sun, M. Su, W. Tang, Q. Zhu and H. Wang, "A robust control scheme based on ISMC for the brushless doubly fed induction machine," IEEE Transactions on Power Electronics, vol. 33, no. 4, pp. 3129-3140, April 2018.

[22] W. Xu, A. K. Ebraheem, Y. Liu, J. Zhu, M. G. Hussien and O. M. Elbabo Mohammed, "An MRAS Speed Observer Based on Control Winding Flux for Sensorless Control of Stand-Alone BDFIGs," in IEEE Transactions on Power Electronics, vol. 35, no. 7, pp. 7271-7281, July 2020.

[23] J. Rodriguez et al., "State of the art of finite control set model predictive control in power electronics," IEEE Transactions on Industrial Informatics, vol. 9, no. 2, pp. 1003-1016, May 2013.

[24] M. S. Boger, A. K. Wallace, R. Spee and Ruqi Li, "General pole number model of the brushless doubly-fed machine," in IEEE Transactions on Industry Applications, vol. 31, no. 5, pp. 1022-1028, Sept.-Oct. 1995.

[25] J. Poza, E. Oyarbide, D. Roye and M. Rodriguez, "Unified reference frame dq model of the brushless doubly fed machine," in IEE Proceedings - Electric Power Applications, vol. 153, no. 5, pp. 726-734, September 2006.

[26] Y. Shtessel, C. Edwards, L. Fridman, and A. Levant, "Sliding mode control and observation," New York, NY, USA: Birkhauser, 2014.

[27] J. Mishra, L. Wang, Y. Zhu, X. Yu and M. Jalili, "A novel mixed cascade finite-time switching control design for induction motor," IEEE Transactions on Industrial Electronics, vol. 66, no. 2, pp. 1172-1181, Feb. 2019.

[28] C. Lascu, A. Argeseanu and F. Blaabjerg, "Super twisting sliding-mode direct torque and flux control of induction machine drives," IEEE Transactions on Power Electronics, vol. 35, no. 5, pp. 5057-5065, May 2020.

[29] Xun Zhao, Hui Wang, Hanbing Dan, Zhengzhang Di, Yao Sun, Mei Su, Marco Rivera, Patrick Wheeler, "A cascade PI-SMC method for brushless doubly-fed induction machine with matrix converter," presented at the 35th Annual IEEE Applied Power Electronics Conference \& Exposition, New Orleans, Louisiana,2020.

[30] Gui Weihua, Sun Yao, Qin Hengsi, Yang Chunhua and Su Mei, "A matrix converter modulation based on mathematical construction," in 2008 IEEE International Conference on Industrial Technology, Chengdu, pp. 1-5.

[31] Sajjad Tohidi, "Analysis and simplified modelling of brushless doubly-fed induction machine in synchronous mode of operation," IET Electr. Power Appl, vol. 10, no. 2, pp. 110-116, 2016.
[32] Levant A. "Higher-order sliding modes, differentiation and output-feedback control," International journal of Control, vol.76, pp.924-941, 2003.

[33] L. Harnefors, K. Pietilainen and L. Gertmar, "Torque-maximizing field-weakening control: design, analysis, and parameter selection," IEEE Transactions on Industrial Electronics, vol. 48, no. 1, pp. 161-168, Feb. 2001.

[34] Moreno J A, Osorio M. "Strict Lyapunov functions for the super-twisting algorithm," IEEE transactions on automatic control, vol.57, no.4, pp.1035-1040, 2012.

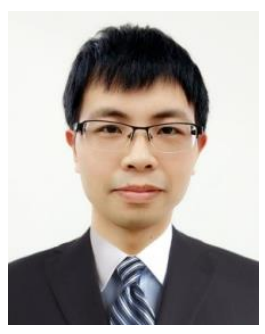

Hui Wang received the B.S. degree in automation, the M.S. degree in electrical engineering, and the $\mathrm{Ph} . \mathrm{D}$. degree in control science and engineering from Central South University, Changsha, China, in 2008, 2011, and 2014, respectively.

Since 2016, he has been with the School of Automation, Central South University. His research interests include matrix converters, DC/DC converters, and solid-state transformers.

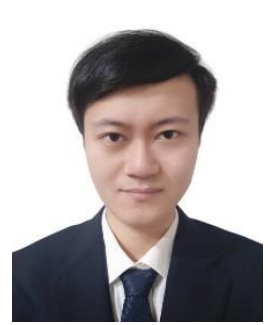

Xida Chen received the B.S. degrees in electrical engineering and automation from Changsha University of Science and Technology, Changsha, China, in 2017.

$\mathrm{He}$ is currently pursuing the Ph.D. degree in control science and engineering at Central South University, Changsha, China. His research interests include matrix converters and model predictive control for power converters.

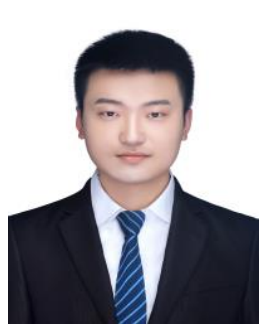

Xun Zhao was born in Heilongjiang, China, in 1996. $\mathrm{He}$ received the B.S. degree in electrical engineering from Central South University, China, in 2018.

$\mathrm{He}$ is currently pursuing the M.S. degree in electrical engineering. His research interests include modeling and control of power electronics converters.

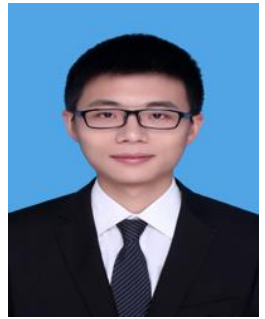

Hanbing Dan was born in Hubei, China, in 1991. He received the B.S. degree in Automation, and Ph.D. degree in Control Science and Engineering from Central South University, Changsha, China, in 2012, and 2017, respectively. He was a visiting researcher in Faculty of Engineering at the University of Nottingham, United Kingdom during 2017. He is currently an associate professor with the School of Automation, Central South University, China.

His research interests include power converter, motor control, model predictive control, fault diagnosis. 


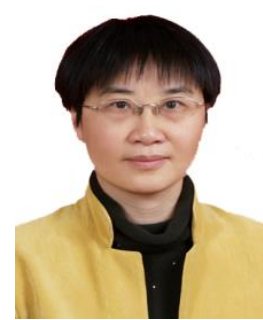

Mei Su (Member, IEEE) was born in Hunan, China, 1967. She received the B.S. degree in automation, the M.S. degree in automation, and the Ph.D. degree in control science and engineering from Central South University, Changsha, China, in 1989, 1992, and 2005, respectively. She has been a Full Professor with the School of Automation, Central South University. She is currently an Associate Editor of the IEEE Transactions on Power Electronics.

Her research interests include matrix converter, adjustable speed drives, and wind energy conversion system.

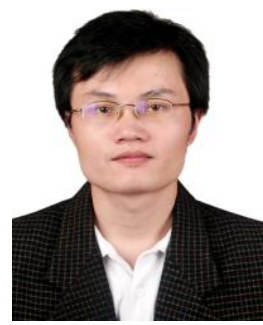

Yao Sun (Member, IEEE) was born in Hunan, China, in 1981. He received the B.S., M.S. and Ph.D. degrees from Central South University, Changsha, China, in 2004, 2007 and 2010, respectively. He has been a Professor with the School of Automation, Central South University, China.

His research interests include matrix converter, microgrid and wind energy conversion system.

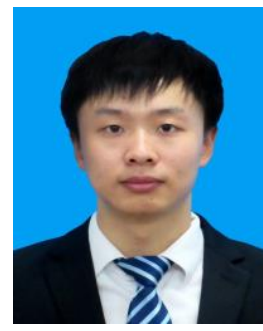

Fan Zhang was born in Hunan, China, in 1994. He received the B.S. degree in electrical engineering and the automatization, and master degree in electric engineering from Central South University, Changsha, China, in 2016, and 2019, respectively. $\mathrm{He}$ is currently an engineer at GAC R\&D Center. development of high-performance control platforms based on FieldProgrammable Gate Arrays.

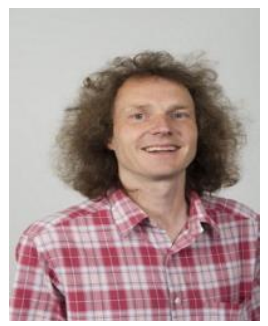

Patrick Wheeler (Fellow, IEEE) received his B.Eng. (Hons.) degree in 1990 from the University of Bristol, UK. He received his $\mathrm{PhD}$ degree in Electrical Engineering for his work on Matrix Converters from the University of Bristol, UK in 1994. In 1993 he moved to the University of Nottingham and worked as a research assistant in the Department of Electrical and Electronic Engineering. In 1996 he became a Lecturer in the Power Electronics, Machines and Control Group at the University of Nottingham, UK. Since January 2008, he has been a Full Professor in the same research group. He was Head of the Department of Electrical and Electronic Engineering with the University of Nottingham from 2015 to 2018. $\mathrm{He}$ is currently the Head of the Power Electronics, Machines and Control Research Group, Global Director of the University of Nottingham's Institute of Aerospace Technology and was the Li Dak Sum Chair Professor in Electrical and Aerospace Engineering. He is a Vice President of the IEEE PELs and was an IEEE PELs Distinguished Lecturer from 2013 to 2017. He has authored or coauthored 750 academic publications in leading international conferences and journals.

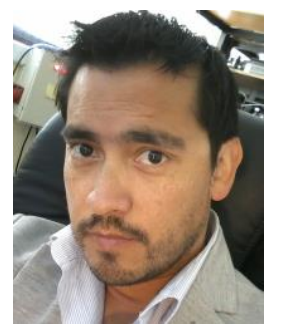

Marco Rivera (Senior Member, IEEE) received his B.Sc. in Electronics Engineering and M.Sc. in Electrical Engineering from the Universidad de Concepcion, Chile, in 2007 and 2008, respectively. He received his PhD degree from the Department of Electronics Engineering, Universidad Tecnica Federico Santa Maria, in Valparaiso, Chile, in 2011 with a scholarship from the Chilean Research Fund CONICYT. During 2011 and 2012, Prof. Rivera held a Post Doctoral position and worked as part-time professor of Digital Signal Processors and Industrial Electronics at Universidad Tecnica Federico Santa Maria. Currently he is an Associate Professor in the Faculty of Engineering at Universidad de Talca, Curico, Chile. Prof. Rivera Abarca was awarded a scholarship from the Marie Curie Host Fellowships for early stage research training in electrical energy conversion and conditioning technology at the University College Cork, Cork, Ireland in 2008. In 2012, Prof Rivera was awarded the Chilean Academy of Science Doctoral Thesis Award (Premio Tesis de Doctorado Academia Chilena de Ciencias), for the best PhD thesis published in 2011, selected from among all national and international students enrolled in any exact or natural sciences program in Chile and he was awarded as an Outstanding Engineer in 2015.

$\mathrm{He}$ is the Head of the Laboratory of Energy Conversion and Power Electronics (LCEEP) and the Technology Center for Energy Conversion (CTCE). His research interests include matrix converters, predictive and digital controls for high-power drives, four-leg converters, renewable energies and 